\title{
The Approach of the Business Sector to Responsible Research and Innovation (RRI)
}

\author{
Annamaria Inzelt \\ Funding Director; and Honorary Professor, annamaria.inzelt@gmail.com
}

Laszlo Csonka

Executive Director, csonka.laszlo@penzugykutato.hu

IKU Innovation Research Centre, 24 Felhévizi u., HU-1023 Budapest, Hungary

\begin{abstract}
This paper focuses on the attitudes and approaches of businesses to responsible research and innovation (RRI), in that this emerging concept anticipates and assesses the various effects of research and innovation practice. The importance of this issue is highlighted by recent scandals in the automotive industry (and elsewhere). Much of our attention is devoted to corporate responsibility in the fields of research and innovation, an important value that goes beyond research. Our investigation was based on 27 case studies relating to companies from 14 European countries. The selection criteria went beyond those used most frequently in RRI studies, covering fields wider than the emerging techno-sciences. This explorative research makes it easier to comprehend the feasibility and importance of empirical research. This feasibility study is a first step in obtaining relevant knowledge about the progress of European companies moving towards responsible
\end{abstract}

Abstract

\section{Keywords:}

responsible research and innovation (RRI); corporate social responsibility (CSR); socioeconomic impact; sustainable development; ethical approach research and innovation. The cases investigated show the existing dimensions and mechanisms of RRI in creating and identifying the barriers hindering RRI. The analysis has shown that RRI is little known as a comprehensive concept at companies, but many address RRI topics under other concepts such as corporate social responsibility (CSR) or sustainability. Altogether, several features of RRI are well covered by large European companies, and the differences in business RRI activities and their scope may be explained by variations in the character of the entities concerned (size, ownership, industry). The novelty of this paper lies in its investigation into the business practices of RRI, not only as a whole, but by opening up 'the black box' to see which elements are more mature and which ones need further improvement. It also uniquely illustrates how different business characteristics influence the treatment of various RRI dimensions.
Citation: Inzelt A., Csonka L. (2017) The Approach of the Business Sector to Responsible Research and Innovation (RRI). Foresight and STI Governance, vol. 11, no 4, pp. 63-73. DOI: 10.17323/2500-2597.2017.4.63.73 
$\mathrm{I}$

$\mathrm{n}$ the age of the knowledge economy, the question of responsibility is at the heart of innovation. That societies must innovate is a fact, but at what cost to human life and the environment? This question is posed to various actors in innovation systems and occurs at different levels of society from the individual to global. A relevant example is the Volkswagen diesel scandal, which illustrates perfectly why responsible research and innovation (RRI) is a concern for the business sector. The company used a software code to mislead US testing procedures for nitrogen oxide simply to achieve more turnover and profit on the US market. ${ }^{1}$ The cars incorporated serious technical knowledge and had many innovative elements, but unresolved technical problems were disguised by software designed to deceive. So, the product as a whole epitomized irresponsible innovation.

This paper focuses on responsible research and innovation (RRI) by business organizations and, in the business sector, responsible innovation may be associated with all types of innovation: product, process, organizational, and marketing [OECD, Eurostat, 2005]. This paper focuses only on product and process innovations related to various techno-scientific areas and innovation, which is linked to research-based practices of technological development either for totally new or modified innovations. The companies not only bear the responsibility for the individual (their employees) and at the organizational level, but they also have a wider effect on national and international society through their linkages with other actors in the innovation system.

Responsibility is socially and politically relevant and influences the governance of the respective field [Grunwald, 2011]. The concepts of corporate responsibility (CR) [Goodpaster, 1983] and corporate social responsibility (CSR) [McWilliams, Siegel, 2001; et al.] are known and well embedded at large companies. A less well-known concept is the recently emerging term 'responsible research and innovation' (RRI) [Owen et al., 2012; et al.], which is an approach which anticipates and assesses future effects and societal expectations with regard to research and innovation, with the aim of fostering the design of inclusive and sustainable research and innovation. The meaning of responsibility in research is deeply rooted in the research community's knowledge and practice. However, knowledge of responsibility in innovation is much more limited, and we focus our attention on the company's responsibility regarding innovation, aiming to assert its importance in terms of values.

The literature has identified many possible dimensions or forms of RRI, and our research is based on previous studies and case studies, the better to gather knowledge on RRI in actual company practice and recognize different forms of RRI as identified elsewhere in the literature.

In our empirical analysis, we tried to deduce how the characteristics of individual companies influence their involvement in different RRI activities, by such questions as: How is the RRI concept understood and used by European companies? What are the main influencing factors for the involvement of companies in various RRI activities? Which features of RRI are important for companies (including both public and private activities)? Which factors are achieved by applying relevant mechanisms? What are the main burdening factors of RRI at a company level?

One of the novel contributions of the present empirical study originated in the composition of the sample. The selected companies cover a much broader field than that of emerging techno-sciences. The analysis shows clearly that RRI is an issue for companies in all sectors.

\section{Conceptual Background of RRI in a Rapidly Changing Environment}

The issue of responsible innovation (and responsible development) emerged relatively recently. In the last decades of the $20^{\text {th }}$ century, several radical innovations such as nanotechnology (for medicine and healthcare), information technology, biotechnology (genomics, genetically modified crops), synthetic biology, neurotechnology, robotics, and geoengineering led to the emergence of new sectors, called emerging technosciences, and, as a consequence, to increased responsibility.

The concept of RRI and its predecessors have a rich history in the literature (summarized by [Pavie et al., 2014]). This section does not examine this, although we highlight certain recent notions that are important to support this empirical analysis. Before discussing responsible innovation, however, we do make a little detour into the meaning of innovation in the $21^{\text {st }}$ century.

"Innovation is about change and this can take place along a spectrum of increasing novelty, from simple incremental improvements ... through to radical changes that are completely new to the world." [Bessant, 2013 , p. 1] In the $21^{\text {st }}$ century, radical innovations representing discontinuous events of technological change usually are the result of systematic $\mathrm{R} \& \mathrm{D}$, either in corporate laboratories or academic organizations and raise more issues of responsibility than do incremental innovations. (The latter are modifications to existing systems of products and processes, usually as a result of inventions and improvements suggested by engineers or users.) However, incremental innovations raise also many issues of responsibility, such as the adaptation of Chernobyl-type nuclear power stations. Innovation is a collective process fuelled by different kinds of knowledge and involves many actors within companies and from the outside world, as Rothwell described in his pioneering work [Rothwell, 1992]. Intra- and inter-organizational links are crucial and highly networked, such multi-actor environments are the emergent properties of the innovation system. Opening up innovation to employees, users, financiers, and others is important. So "innovation, whether technological or otherwise, is not simply a new set of techniques for doing things, but also ultimately new social practices and even institutions that transform the ways in which human beings interact with the world around them." [Grinbaum, Groves, 2013, p. 119].

\footnotetext{
The cars emit up to 40 times the allowable levels of air pollutants, which are called nitrogen oxides (NOx). This environmental pollution is dangerous since all emissions of nitrogen oxide are a major contributor to serious respiratory disease [Ghose, 2015].
} 
Nowadays innovation is a collective process that requires a collective approach to responsibility. Responsible innovation should be distinguished from mere innovation as not all innovations are good things [Bessant, 2013, van den Hoven, 2013]. Innovations may have negative consequences beyond positive benefits either in the introductory or a later stage (such as contergan or thalidomide, nuclear weapons, and the Fukushima nuclear power station).

The discussion on the societal and economic impact of science and innovation and the recognition of major challenges for mankind are also in the focus of RRI in governmental funding decisions on research and innovation. Responsibility has become a worldwide issue in many contexts, among them within developing countries. An important type of responsible innovation involving a societal dimension is 'frugal innovation, which emerged in developing countries. Frugal innovation creates value in socially desirable ways. This type of responsible innovation for people at the base of the pyramid is responding to some of the grand societal challenges to perform sustainable development [European Commission, 2016]. ${ }^{2}$

RRI is an emerging concept that influences companies' innovation activities. The term itself refers to an approach that is spreading rapidly throughout the European Union and has become an important element of the Horizon2020 (2014-2020 program period of EU). ${ }^{3}$ The working definition for EU projects, including ResAgora is:

"Responsible Research and Innovation is a transparent, interactive process by which societal actors and innovators become mutually responsive to each other with a view to the (ethical) acceptability, sustainability, and societal desirability of the innovation process and its marketable products (in order to allow a proper embedding of scientific and technological advances in our society)." [von Schomberg, 2013].

This concise definition expresses well that innovating responsibly entails a continuous commitment to four components: to be anticipatory, reflective, inclusively deliberative, and responsive [Owen et al., 2013, p. 29]. From a general point of view, however, the framing of responsible innovation has to move further and identify the dimensions of responsible innovation. For the purposes of empirical investigation, the four RRI segments were operationalized in the ResAgor $\mathrm{A}^{4}$ project by a dimension based on the previous experience of national experts. (Table 1)

Each dimension is an umbrella term. They cover many different activities and mechanisms. The types and characteristics of the studied companies influence how sophisticated the RRI dimensions are and which instruments are used to translate RRI into practice.

New or deepened responsibilities have broadened the circle of actors who have or may have a role in RRI. The agenda of responsibility differs by actor. The following actors should bear their responsibility in the research and innovation process: scientists, universities, innovators, businesses, policy-makers, and research funders. The state is responsible for defining the risks of technologies through product authorization procedures and product liability law, as well as ensuring market operators compliance [von Schomberg, 2013]. The responsibility of business organizations is to work to create socially desirable products.

Moreover, different traditional RRI cultures, their previous involvement in technological assessment, foresight exercises, science in society, and stakeholder communication may also influence the presence and

Table 1. Key RRI Segments and their Dimensions Operationalised for a Corporate Study

\begin{tabular}{|l|l|}
\hline \multicolumn{1}{|c|}{ Segments } & \multicolumn{1}{c|}{ Operationalized dimensions for investigation at the company level } \\
\hline Anticipatory & Societal Challenges \\
\hline Reflective & $\begin{array}{l}\text { - Sustainability } \\
\text { - Ethics } \\
\text { - Environment } \\
\text { - Health } \\
\text { - Gender equality } \\
\text { - Cultural heritage }\end{array}$ \\
\hline $\begin{array}{l}\text { Inclusively } \\
\text { deliberative }\end{array}$ & $\begin{array}{l}\text { Engagement: } \\
\text { - Societal actors (general public, civil societies, laypeople) } \\
\text { - Public engagement (scientists and business men) } \\
\text { - Orticipation of users (customers, consumers, patients), }\end{array}$ \\
\hline Responsive & $\begin{array}{l}\text { - Education, training, and investment in human resources } \\
\text { - Open access } \\
\text { - CSR }\end{array}$ \\
\hline Source: compiled by the authors.
\end{tabular}

\footnotetext{
${ }^{2}$ Frugal (also known as inclusive or grassroots) innovation is the process of reducing the complexity and cost of a good by removing non-essential features of, for example, a car or phone, or to develop specific goods, and this has the potential of addressing new markets or economically marginalized areas. This may also involve the re-engineering of traditional techniques by re-visiting the scientific base of technologies and know-how elaborated over the centuries. Frugal innovation is not revolutionary in terms of research and technology, but it has important novel value and is socially very useful. The investigation of frugal innovation goes beyond this study since none of the selected companies are involved in frugal innovation.

${ }^{3}$ The EC and the scientific community are approaching an internationally harmonized definition. See an overview in [Buzás, Lukovics, 2015].

${ }^{4}$ The full title of the project is «Responsible Research and Innovation in a Distributed Anticipatory Governance Frame. A Constructive Socio-Normative Approach». For more details see http://res-agora.eu/ (last accessed 21.04.2017).
} 
Table 2. The Realization of RRI Dimensions by Type of Companies

\begin{tabular}{|c|c|c|c|c|c|}
\hline & Total (nr.) & MNCs & International & Subsidiary & Domestic \\
\hline All respondents & 27 & 9 & 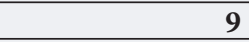 & 6 & 3 \\
\hline \multicolumn{6}{|c|}{ Frequent occurrence of dimensions (Nr. of firms) } \\
\hline Environment & 21 & 8 & 8 & 4 & 1 \\
\hline Engagement & 19 & 7 & 8 & 3 & 1 \\
\hline Ethics & 17 & 9 & 7 & 1 & 0 \\
\hline Sustainability & 17 & 7 & 7 & 3 & 0 \\
\hline CSR & 17 & 5 & 8 & 3 & 1 \\
\hline Gender equality & 15 & 5 & 6 & 3 & 1 \\
\hline Societal challenges and policy & 15 & 7 & 3 & 3 & 2 \\
\hline Education & 14 & 5 & 4 & 4 & 1 \\
\hline Health & 10 & 2 & 4 & 3 & 1 \\
\hline Open access & 7 & 3 & 3 & 1 & 0 \\
\hline Cultural heritage & 3 & 2 & 0 & 1 & 0 \\
\hline
\end{tabular}

Notes:

A multinational corporation (MNC) is usually a large corporation incorporated in one country and has worldwide activities that are centrally controlled by the parent companies.

An international company is incorporated in one country and has activities in at least two countries. It is geographically less dispersed than MNCs.

A subsidiary is a firm that is fully or partially owned by a MNC or an international company.

Source: Authors' compilation from case studies.

importance of various RRI dimensions. This paper, however, does not deal with these aspects [Grunwald, 2011; Mejlgaard, Bloch, 2012; Tsipouri, 2012].

\section{Sampling and Methodological Issues}

This explorative research has employed qualitative selection criteria for companies. The investigation should focus on large companies: either being large in terms of their turnover, profit, or important in their countries. Other criteria include that a company frequently introduces R\&D-based innovations, and that it is known to have established CSR (and RRI) policies. These selection criteria went beyond most RRI studies covering broader fields than emerging techno-sciences since they included companies from other sectors with traditional technologies in the investigation.

The ResAgorA project studied companies from 16 EU member states which differ by size, level of development, strength of institutional setting, the role of NGOs and activist groups, and traditions in any kind of responsibility.

The research sample covers 27 companies with full case studies from 14 countries. We have partial information on five companies from two countries not included in the analysis of the case studies. ${ }^{6}$ The sample is not representative, as the approach for selection was explorative-qualitative. Despite this, the set of investigated companies allows for formulating typologies of the companies from the perspective of the importance of RRI in the business sector. The importance of different dimensions of RRI in company practice is another important component of the empirical research. Except for three SMEs, all other companies are large, but of varying sizes (from 1,000 to 77,000 employees). By type, nine companies are multinational giants, and another nine are large international companies, of which three are still family-run (Table 2). Six companies are subsidiaries of MNCs and they are also large (except for one medium-sized firm) in statistical terms, but they are much smaller 'large' companies than those that belong to the previous groups. Three are domestic companies, one of which is large, two others are medium-sized (one was founded as a global company). These companies are also export-oriented, but they have no other operations in third countries.

The presence of multinationals and international companies in the sample is important as they are critical actors in research and innovation (RI) processes and in the RRI arena. Internationally operating companies have responsibilities not only in their home countries but also in other countries. Companies from the developed world are responsible also for developing nations. They influence the attitudes in many countries towards RRI through their activities and subsidiaries.

The vast majority of companies are $\mathrm{R} \& \mathrm{D}$-oriented and they introduce radical as well as gradual innovations, including adaptation-based examples. The companies in the sample have different characteristics by their field of R\&D and economic sector. ${ }^{7}$ At several companies, R\&D has focused on multidisciplinary research,

\footnotetext{
Participating countries were: Austria, Czech Republic, Denmark, Finland, France, Germany, Greece, Hungary, Iceland, Ireland, Italy, Lithuania, the Netherlands, Poland, Spain, and the UK.

${ }^{6}$ The case studies were prepared by national experts: Erich Griessler (AUT), Morten Velsing Nielsen (DEN), Gema Revuelta, Octavi Planelis \& Nuria Saladie (ESP), Mika Nieminen \& Veiko Ikonen (FIN), Elise Tancoigne \& Allison Loconto (FRA), Stephanie Daimer (GER), Lena Tsipouri (GRE), Annamaria Inzelt (HUN), Svandis Nina Jonsdottir \& Eva Dogg Diego Thorkelsdottir (ISL), Simone Arnaldi (ITA), Loreta Tauginiene \& Saule Maciukaite-Zviniene (LIT), Adri Albert de la Bruheze \& Gido Akse (NED), Jan Koslowski (POL) and Kalle Stahl Nielsen \& Dana Abi Ghanem (UK).

The selection of companies to be interviewed was hindered by the willingness of those approached. The sample contains companies from those pre-selected who were ready to respond and interested in the topics. Apart from positive experiences with
} 
and in others one or two fields may be identified from traditional to newly emerging fields such as biological, biomedical, chemistry, biochemical, physics, energy, ICT, and environmental science. The industrial branches of companies are also varied, such as pharmaceuticals, cosmetics, chemicals, building materials, machinery, ICT, electronics, construction equipment, the automotive industry, and the energy and fuel sector. These sectors differ in terms of environmental sensitivity or life sensitivity, which makes them either strictly regulated or only generally regulated sectors. These variations produce different responsible behaviors at the company level.

Methods of research were: Analyzing publicly available documents focusing on CSR and RRI activities to learn how companies regulate and treat CSR and RRI was the basic source of information, but face-to-face or telephone interviews with relevant personnel at companies formed the lion's share of the investigation. The preferred method of selection for interviews was to ask two different professionals at a high level (head of a department or senior employee) in the R\&D department and the division responsible for working with CSR or related issues. The case studies followed the same structure. The first section of case studies briefly described the business characteristics and RDI activities of the company, whilst the second identified how the companies addressed RRI issues, and which dimensions of RRI might be identified at the organization. The third section described the relationships between RRI and CSR, whereas the fourth section focused on mechanisms that actually achieve RRI. The fifth and final section summarized the perceived barriers to achieving RRI.

\section{RRI in the Making (Main Findings)}

One of the lessons of the case studies is that all companies are familiar with the old concepts of CR and CSR and they have many such mechanisms in their practice. The term RRI is much less frequently used. According to our empirical findings, the meaning of RRI is better known among companies involved in EU projects and/or active in regulated sectors. The bulk of the companies investigated is familiar with the term RRI and use it in practice. Others do not use the term but some RRI features may be identified in their practice, usually under the term CSR, with RRI not recognized independently, although the two are interconnected.

Some companies explained how they define RRI for themselves. For example:

- L'Oreal (France): Research and innovation responsibility is "developing efficient and affordable products that meet consumers' expectations; products that are the best in terms of quality, safety, environmental and social impact". According to them, responsible innovation is made of five pillars: (1) product safety, (2) environmental respect, (3) ethics, (4) fair procurement, and (5) adaptation to global diversity.

- DSM (The Netherlands) participates in the chemical industry's Responsible Care Program. "The responsible care program that explicitly mentions responsible innovation promotes the improvement of health, safety, environmental performance and communication with stakeholders in order to create sustainable innovation and supports products and (innovative) technologies that reduce energy use, minimize greenhouse gas emissions, and decreases the human footprint on our earth and its resources.'

The companies that have RRI awareness cover more dimensions of RRI than the others. However, a few dimensions of RRI may be observed at the companies who are not familiar with the term or simply do not use it. The implicit (or hidden) RRI activities may originate from limited knowledge about the subject of RRI, from limited attention to this kind of responsibility or just neglecting the term. Good examples of the latter are BASF and Siemens where RRI is an integral part of corporate thinking even if the term is not used. Another good example is Velux (Denmark), which uses the term corporate responsibility instead of CSR and RRI although the company is involved in RRI.

\section{The Presence of RRI Dimensions in Different Groups of Companies}

By their frequency, the RRI dimensions differ in the sample. The presence of the dimensions was summarized without distinction between those explicitly or implicitly expressed at the investigated companies.

The responsibility relating to the environment and engagement are present at the majority of companies (20 and 19 , respectively).

Many companies devote attention to RRI-related ethics as well as sustainability (17), societal challenges, societal policy (15), and education (14).

Health (9) and open access (7) are mentioned by a few companies inspired by sectoral features (healthrelated sectors and ICT, data producing companies). Some companies from other sectors discussed how controversial an issue open access is for them. The involvement of profit-based organizations in research (including universities) means that the process has become more secretive than ever. The business community alone cannot hope to achieve its full reward for inventions in patent-dominated industries if they allow open access instead of patenting. ${ }^{8}$ Some companies active in basic research mention that they would accept open access, but would prefer to publish in leading journals.

the bulk of busy RDI leaders and CSR/RRI professionals, there were some difficulties with (potential) respondents. Following a first approach, several companies refused to give an interview. Another problem occurred at the large companies where the second professional explicitly or implicitly (always postponed) refused the interview or delegated it to the PR department, which was hardly relevant for the study. Another problem emerged during the approval procedure. Some companies tried to seriously modify the information from the original interview using PR materials on project websites.

${ }^{8}$ Challenging this situation, Tesla has made their patents related to vehicle fuel cells available. Their step towards open access was followed later by Ford and Toyota for electric vehicles. 
Table 3. Differences in the Frequency of RRI Dimensions by Regulated and Non-Regulated Companies

\begin{tabular}{|l|r|r|r|}
\hline \multicolumn{1}{|c|}{ Rank of dimensions (for total) } & Total (nr.) & Regulated (\%) & Non-regulated (\%) \\
\hline All respondents & $\mathbf{2 7}$ & $\mathbf{1 1}$ & $\mathbf{1 6}$ \\
\hline Environment & 21 & 91 & 69 \\
\hline Engagement & 19 & 73 & 69 \\
\hline Ethics & 17 & 64 & 63 \\
\hline Sustainability & 17 & 55 & 69 \\
\hline CSR & 17 & 36 & 81 \\
\hline Gender equality & 15 & 55 & 56 \\
\hline Societal challenges and policy & 15 & 73 & 44 \\
\hline Education & 14 & 73 & 38 \\
\hline Health & 10 & 36 & 38 \\
\hline Open access & 7 & 27 & 25 \\
\hline Cultural heritage & 3 & 9 & \\
\hline Source: compiled by the authors. & & & \\
\hline
\end{tabular}

Almost all companies devote attention to gender equality as one of the universal equalities together with race and age, and this aspect is included in CSR or in other policies replacing CSR. It is almost entirely interpreted as the equal representation of men and women at all levels and not as considering gender in the innovation process. Some companies take into consideration whether or not women are pregnant and if they need special health protection during the research and innovation process.

Preserving and further developing the cultural heritage is infrequently mentioned by companies (3). These examples belong to CSR and they do not have RRI features.

The next paragraphs focus on the differences by groups of companies relating to the dimensions of RRI. The small sample allowed us to split the companies into two groups: regulated and unregulated industries (in short, we call the companies that belong to regulated sectors regulated companies). This criterion is important in the context of RRI.

The companies that belong to the regulated sector have a longer tradition of dealing with several dimensions of RRI and have more sophisticated mechanisms than those sectors neutral to civil society. All companies that belonged to the 'regulated' group were health-related and the majority belonged to the pharmaceutical industry, with other groups involved in chemical-, biological-, and biotechnology-based R\&D activities. One of the non-pharmaceutical companies was a large cosmetics company and another one was active in orthopedics.

Table 3 shows the frequency of RRI dimensions by these groups. When investigating the presence of the various dimensions of RRI at the companies, we took into account both explicit and implicit RRI activities whether or not companies use the RRI terminology.

All regulated companies (11), except one domestic example, mentioned environmental awareness, environment protection programs, and reducing the ecological footprint. Overall, engagement is also very frequently mentioned. A slightly larger proportion of regulated companies raised this than did nonregulated ones. Engagement covers a very broad range of actors (see Table 1).

Education is more frequently met at regulated than non-regulated companies. Education is again an umbrella type of dimension that covers many different activities. Some of the activities are closely interwoven with CSR. Few companies, whether they are regulated or non-regulated, arrange specific training for the staff on RRI-related matters with developing or adapting new training materials.

The difference in the RRI-related involvement in societal challenges and policy as well as in education is larger between regulated than non-regulated companies.

Societal challenges and societal policy are present either in companies' R\&D strategies or the companies' overall strategies. The most frequently mentioned major challenge is climate change and companies are searching for the relevant methods to diminish the ecological footprint of their products and processes. However, this dimension is not a strongly reflected issue since the documents mention it generally, however, no concrete actions and mechanisms are attached to them.

A higher share of non-regulated companies mentioned the importance of CSR than regulated firms, but we may assume that several non-regulated companies focused on general CSR and not on RRI-related CSR activities. Sustainability is more important for regulated than non-regulated companies. There are two other dimensions in which the RRI content is not very strong. Gender equality and cultural heritage belong more to CSR than RRI in the practice of companies.

In the different frequency of RRI dimensions, another typology of the companies can bring additional important information. If they are MNCs, internationalized, subsidiaries of earlier MNCs, or domestic companies, we could observe some different influences on their own decision-making power in RRI. ${ }^{9}$

This small research sample illustrates how important it is to investigate RRI dimensions by these different types of companies.

\footnotetext{
${ }^{9}$ The sample was too small to employ both important criteria simultaneously.
} 
There are differences among the companies in their CSR and RRI attitudes by their decision-making type: some subsidiaries are practically clones of their parent companies with limited potential to adjust to their home country, whilst others have some autonomy.

Ethics and sustainability are crucial for a larger number of MNCs and internationalized companies and less so for subsidiaries and domestic companies. Ethics are an important issue for all multinationals and were also mentioned frequently by other companies, but only by one of the six subsidiaries. The meaning of ethics is better developed (and understood) in the context of research than in that of innovation. The companies active in the regulated health sector are more familiar with this dimension than others (e.g., concerning testing on animal or on human subjects and the ethics of biomedical research). The ethical process for developing research and innovation programs and an ethical supply chain are among the issues. In any sectors where privacy is an issue, the companies' ethical code regulates this field. Some other ethical issues such as anti-corruption, anti-bribery, and child protection were mentioned, but these important ethical topics do not belong to RRI. As regards sustainability, it is possible that there are no major differences among MNCs, internationalized, and other companies. The companies with a more sophisticated organizational structure, a more detailed annual report, mentioned this issue, whilst others may have the same kinds of activity under different names. At some companies, the responsibility concerns people and the planet (and profit). Another difference may originate in a definitional problem. Some companies understand sustainability in a very complex way that goes beyond products and services. In their case, the internal processes should be sustainable in terms of using little energy and generating no environmental harm. Measures to achieve this are setting (external and internal) goals and targets, and monitoring and reporting performance. Beyond that, there is some overlap between the three dimensions: sustainability, environment, and health. Some companies have mentioned the same things in each dimension, while others have referred only to one, such as environmental sustainability, sustainable agriculture, and consumption.

Significant differences may be observed if we study different kinds of engagement. For example, policy engagement was mentioned only by some MNCs as a direct form. Multinational companies have their own roles to play in international fora. Some others highlighted policy engagement that can be achieved through associations. Public (civil society) engagement was more frequently mentioned but has different meanings. Some companies follow one-way communication, that is, by informing the public through lectures and meetings about research and innovation (R\&I). A more sophisticated form of engagement relies on twoway communication, debates and dialogues and not solely lectures, when scientists and businessmen listen to the public to understand the public perception of new technologies, this was, however, less frequent.

A few companies involve their suppliers and other stakeholders, which would be appropriate in an open innovation system. Several companies do not involve the public even if their activities will have major effects on them. The involvement of users (such as patients) is more common and sometimes such RRI activity is interwoven with marketing.

Education is important for more subsidiaries and domestic companies than for other types of firms. Education and training is thus a critical endeavor for responsible innovation, and not only for the current crop of future workers. Involvement in the development of teaching curricula to cover research and innovation ethics, environmental and health issues, and emerging technologies are also on the agenda of some of the large companies. The majority of companies feel responsible for future generations and thus science education is addressed. STEM (science, technology, engineering, and math) education is supported in various ways. (See more in the section on mechanisms).

CSR as a dimension of RRI was mentioned by many companies but there is no clear line between CSR and RRI. RRI is more frequently a part of CSR than vice-versa. In the frequency calculation of dimensions, we have included all companies where CSR covers RRI and we have negligible information on CSR as a dimension of RRI. In our opinion, the role of CSR is different from other factors. Not only conceptually, but also practically, it is doubtful whether it has a role to play as a component of RRI.

\section{Mechanisms Achieving RRI}

Different instruments and actions may be used to translate RRI into practice. Naturally, all regulated companies at least have regulation-related mechanisms and some of the companies from the non-regulated group have also introduced important RRI mechanisms. At several others, CSR mechanisms provide good tools for RRI.

Regulated pharmaceutical companies follow the principles of replacement, reduction, and refinement in the conduct of research involving animal testing to support the well-being of animals. Good laboratory practices, good clinical practices, and pharmacovigilance are among the priorities. The national permission and control system strengthens RRI practice (such as Richter (Hungary), L'Oreal (France), Ossur (Iceland), Pharmathen (Greece), DSM (The Netherlands) or 4Medicine Rek (Poland)).

The importance of RRI is expressed in the companies' documents, indices, employed mechanisms, and their institutional structure. The role of RRI-related institutions is to facilitate many RRI dimensions and coordinate the collaboration of units' responses to RRI challenges. There are different variations at the companies: a dedicated department, a group within a department, chief officer in the upper hierarchy, committees, or combinations of these solutions. Such organizations include the 'Resourcefulness Unit' at OMV, Austria; the Department of Ethics and Chief Sustainability Officer (with representatives from other departments) at L'Oréal, France: or the Committee of Ethics, Environment and Sustainable Department at Firm2, France ${ }^{10}$ ).

${ }^{10}$ This and some other sample companies were ready for interviews on the condition of anonymity. 
The mechanisms for achieving RRI are various. Some mechanisms are common among regulated companies: the institutionalization of responsibility issues at dedicated departments, as well as the use of soft laws, contract clauses, audits, and international indices and metrics to assess their progress. However, specific mechanisms are also developed within each company to tackle the specific challenges they face, for instance, safety at work versus affordable products.

A good sign of RRI awareness appears if companies measure their RRI performance and are happy to be listed in the relevant international rankings. The best RRI performing multinationals are listed on the Dow Jones Sustainability Index (such as Rolls Royce (UK) and Firm 2 (France)). Some others use these indices for monitoring their own RRI performance and approach the best performers (e.g., AstraZeneca, UK). Another group of companies measure more dimensions than international ratings do such as OMV Austria which has developed its own 'Key Performance Indicator Dashboard' (KPID) to measure sustainability using 19 indicators. L'Oréal of France developed green indicators (e.g., the level of renewable carbon in the final inputs; eco-toxicity, biodegradability, and water consumption) in order to assess their products and processes. The observable indicators for external as well as self-assessment and monitoring exist in the context of CSR and sustainability.

Many companies (all healthcare-related companies and some others) have created their own procedures, regulations, and directives related to several dimensions of RRI. A few companies use external assessment bodies for assessing their RRI activities (such as Astra Zeneca UK, Novamont Italy, and H\&S Italy).

The existing mechanisms vary by dimension and corporate activity. The influence of the European Union may be observed on the mechanisms. The EU's Code of Conduct, special and general liability regimes, standards, and evaluation systems for funding projects have not only external impacts on companies' RRI efforts but influence the internal mechanisms of the companies.

There are some mechanisms which work for several dimensions, and so it is worth investigating the mechanisms for sustainability, environment, and health. The aim of most companies is contributing to sustainability and positive impacts upon the environment (planet) and health (people). Hence, the majority of companies promote the improvement of health, safety, and environmental performance together. There are a few large companies which devote attention to assessing and evaluating the majority of their products and processes.

The systematic protection of the environment (to be sustainable) is supported by using ISO 1401 standards in product and process development. The certified Environment Management System portfolio (by ISO 9001) and monitoring process strengthens managerial capabilities.

Resource efficiency is also an important issue. Fuel producers and transportation manufacturers promote solutions for alternative fuels. The carbon disclosure project for diminishing carbon emissions is important for all sectors that are still large carbon emitters (carbon dioxide and other greenhouse gases).

Some companies are introducing smart manufacturing processes and recycling methods for processes and end-of-life products, which contribute to conserving resources (water, electricity, and minerals) and to diminishing any ecological footprint.

The key soft mechanisms for ethics are the various codes of conduct formulated by companies. The EU codes of conduct and liabilities either served as models or encouraged companies to design their own codes of conduct. The majority of companies have their own codes, but the importance of RRI issues differ between healthcare-related and other companies. The latter only touch upon RRI issues, whilst the healthcare-related devote significant attention to such issues as bioethics and animal ethics. Few companies have extended this practice to their partners. For example, L'Oréal (France) signed a Charter of Ethics ${ }^{11}$ with suppliers for sustainability commitments and AstraZeneca (UK) formed partnerships with companies that have ethical standards similar to their own.

As the previous section described, engagement relates to many different actors and the mechanisms have to take these into account.

Training seminars for employees provide a shared understanding of the workplace and its values, and a common understanding within companies is an important condition if employees are to be involved. The development of relevant structures facilitates the collaboration between units and responses from channelling units.

Public engagement is not very intensive at the studied companies and most mechanisms focus on creating an informed public. Companies are less interested in listening to public questions, comments, and opinions, even if some companies have experienced market problems due to their neglect of public opinion. A good example of public debate is Velux of Denmark which uses 'demonstration homes' to initiate a debate on the future of housing with both citizens and stakeholders.

General stakeholder engagement may be found at many companies, but RRI-related involvement is not very frequent. If it exists at all, it has different channels: networks and platforms. Four different examples from different techno-scientific areas illustrate this type of engagement.

- A platform at BASF Germany contributes to the nano dialogue to produce information about nanotechnology and exchanges questions and fears associated with it.

- A partnership with diverse stakeholders exists at Novamont, Italy: local authorities work to increase waste-sorting; farmers and their associations work to promote the sustainable production of raw biological materials for industrial processes; mass retailers and CSOs distribute sustainable consumer products and, more generally, a culture of sustainability.

\footnotetext{
${ }^{11} \mathrm{http}: / /$ www.loreal.com/group/governance/acting-ethically/code-of-ethics--a-guide-for-action (last accessed 07.10.2017).
} 
- The EU project's influence on stakeholders' engagement may be illustrated by Esteve, Spain. In the framework of an EU project, the company provided scientific, objective, and comprehensive information to patients on medical R\&D and maintained dialogues with patients. The company disseminates its findings among its partners in the development process (organizations in the Science Park, potential collaborators: pre-university and university students). Presumably the EU project was a good learning exercise and the company will continue this dissemination practice.

- Stakeholder communication may be organized not only at company level but at the sectoral level as well. The Netherlands' chemical industry has organized communication in cooperation with stakeholders in order to create sustainable innovations that reduce energy consumption, minimize greenhouse gas emissions, and decrease the human footprint on the Earth and its resources. Naturally companies are actors in this communication (such as DSM from our sample).

Since education and training cover different target groups, the mechanisms are also varied. Roughly one third of the companies organize annual training sessions on ethical issues and on inclusion for the staff. Mainly researchers and managers are involved. Some other companies have recognized the training as a task but have not yet started.

The responsibility for future generations of researchers and innovators has led to company involvement in STEM education. Many companies support, intellectually and financially, pupils and students of primary, secondary, and tertiary education institutions (e.g., NI Hungary and its parent company in all countries where they have activities). The companies support employees who participate in the teaching programs and other events at schools such as scientific seminars and the provision of educational organizations of all levels with up-to-date tools and equipment.

A few companies also have in-reach programs mainly for university students (from undergraduate to $\mathrm{PhDs}$ ). Students can participate in the company's projects, internships, and various placements for students to develop their skills and budding careers. The students who carry out research projects at their institutions have access to regular advice from the company (such as Richter, Hungary).

Some non-school forms of education are also common among the investigated companies: public lectures, organizing regional and national competitions involving the public in an emerging field of technology, sponsoring scientific festivals and science days are mentioned as measures.

Since several other RRI dimensions hardly exist in the sample, the related mechanisms are also scattered. It seems that open access has sectoral specificity: Esteve Spain (healthcare-related) as a member of an EU public-private consortium collects and publishes data and information through open access on the toxicity of their products during the development and production processes.

If a company devotes its attention to the cultural heritage, it regulates which kind of heritage it is ready to support, prescribes how to allocate the financial resources for that purpose and how to select candidates.

Gender equality is an important issue for the majority of the companies but only few of them have RRI-related specificities. A good RRI-related example is the responsibility for future generations of female professionals that exists at Rolls Royce UK. The company sponsors the UK Female Undergraduate of the Year, where the successful student is offered a paid internship at Rolls Royce, whereas in Germany, a company has sponsored Girls' Day, an event where female secondary school students are encouraged to envision and pursue careers in engineering. Another example relates to gender-specific health issues at Richter, Hungary, where pregnant women stop working in the laboratory and carry out office work.

Overarching mechanisms may be identified at companies serving several dimensions, such as awards. The companies may launch their own awards, for example, AstraZenecas (UK) Annual Global 3Rs (replacement, reduction, and refinement in animal testing) or participate in external award systems. They may compete for external RRI-related awards as well. Another form of encouragement is incentive-based solutions for sustainability, the environment, and safe and healthy working conditions (e.g., Richter, Hungary).

The companies that are using RRI concepts are employing various sophisticated RRI mechanisms. Meanwhile, others that do not have this specific concept employed in practice can be divided into two groups. 1) Companies which have the relevant mechanisms for RRI (3), and 2) companies which have none (5). The lack of RRI-related mechanisms at these five companies may originate in the wishful thinking of companies on one or more RRI dimensions mentioned in their documents only to avoid criticism.

\section{Barriers Impeding RRI}

Identifying the impeding factors of RRI at the company level was not an easy task. Before summarizing the responses on barriers, it must be noted that the interview question was open-ended. The respondents did not get a list of potential barriers to choose from. We were interested what they might come up with if they were thinking about this issue.

The companies that were more familiar with the term and have explicit RRI activities could describe the impeding factors more clearly. Of the 27 companies, 21 identified barrier factors, which are summarized in Table 4.

The first, most important factor was the companies' accumulated (or missing) capabilities (10 companies). This included a lack of competences in dealing with RRI; the existing negative mind-sets or lack of understanding (and information on) RRI; a lack of culture and/or structure to share knowledge (silo thinking, missing links between units); a lack of time for RRI; and a half-hearted move toward the open innovation system. Some other factors, such as a lack of tradition in dialogue and missing capabilities to take into account others' opinions also caused difficulties in arranging RRI in a participatory way. ${ }^{12}$ Even if

${ }^{12}$ This issue depends on a country's characteristics. EU member states are very different in their consensus-seeking traditions. 
Table 4. Main Groups of Barriers Identified by Companies

\begin{tabular}{|l|r|l|}
\hline \multicolumn{1}{|c|}{ Groups of barriers } & \multicolumn{1}{|c|}{$\begin{array}{l}\text { Number of } \\
\text { Companies }\end{array}$} & \multicolumn{1}{|c|}{ List of companies } \\
\hline Capabilities-related issues & 10 & $\begin{array}{l}\text { Kone (FI); LOOreal (FR); Firm\#1; (LT) Firm\#2 (LT); BASF (DE); Siemens (DE); } \\
\text { Medicine Rek (PL); H\&S (IT); Ossur (IS); deCODE (IS) }\end{array}$ \\
\hline Other business priorities & 8 & $\begin{array}{l}\text { OMV (AT), Rolls Royce (UK), Siemens, (DE), H\&S (IT), Firm\#2 (FR), KGHM } \\
\text { (PL), Telefonica (ES; Esteve (ES) }\end{array}$ \\
\hline $\begin{array}{l}\text { Cross-country law, regulatory, and } \\
\text { cultural differences }\end{array}$ & 7 & $\begin{array}{l}\text { Pharmaten \& Titan (EL), Richter (HU), AstraZeneca (UK), Nokia (FI), DSM } \\
\text { (NL); Philips (NL) }\end{array}$ \\
\hline Lack of education & 2 & Ossur (IS); deCODE (IS) \\
\hline Short-termism & 2 & Nokia (FI), Esteve (ES) \\
\hline Intellectual property regimes & 1 & Velux (DK) \\
\hline Source: compiled by the authors. & \multicolumn{2}{|l}{} \\
\hline
\end{tabular}

the company has learnt about the importance of stakeholders' participation in the research and innovation process, it lacks the expert know-how to organize stakeholder workshops. Public engagement in decisions on research and innovation's relevance, sustainability, and so on is burdened by limited scientific literacy and ill-informed lay people.

The second most frequent group of factors was the other business priorities that are much stronger than RRI (8 companies). Sales, marketing, or growth-based management models can hinder RRI. More sustainable products' costs may negatively affect the competitiveness of companies as potential customers often opt for cheaper products and leave other considerations aside. So, RRI effects cannot compete with core businesses and the expectations of high profits. Certainly, the economic risk of research and innovation may also burden RRI if this risk prevents the company from innovating. The latter phenomenon may be evaluated as the post-trauma of the economic crisis when a previously innovative company becomes reluctant to innovate. It is not easy to find the right balance between cost, competitiveness, profit and sustainability, environmental protection, and so on.

For global business operators, the different national regulatory regimes, cultural, and legal regional differences affect their consideration of the RRI dimensions. These companies lack the European governance system of RRI. The existing EU mechanisms that have a positive influence on RRI mechanisms in member states are not enough for them (4 companies).

Regulation means an accepted environment for the companies belonging to regulated sectors. However, the management of the regulations by authorities is an important impeding factor and includes the limited capabilities of regulators and/or permit-issuing actors (length of permit-issuing period). (3 companies)

Only a few companies raised the issue of a lack of education: ethics in science teaching has not existed in their countries. This kind of knowledge is crucial for a basic understanding of ethical dilemmas by the public and by the scientists of tomorrow.

One company raised the issue of the intellectual property regime as a barrier for collaboration (open innovation) that affects RRI. Companies may individually find pragmatic solutions that could satisfy all involved actors but adjusting the IP regime to the needs of $21^{\text {st }}$ century is an important task.

One of the companies brought to light short-termism as a burdening factor for RRI. Sustainability can be a long-term brand asset for the company, but it does not have short-term effects and this fact limits a manager's interest.

\section{Conclusions}

This exploratory research has been an exercise in stocktaking for the existing dimensions and mechanisms of RRI in the making, and it identifies the barriers hindering RRI.

The analysis has shown that the concept of RRI has slowly penetrated business practice. The understanding of the concept is influenced by sectoral characteristics and the national context. Even in the case of companies that are familiar with the term RRI and may identify some explicit activities, CSR hides (or covers) other RRI elements. Several dimensions are well covered by large companies. However, many companies address RRI topics under other concepts such as CSR, community development, diversity management, gender equality, and sustainability. In the latter cases, the companies could not identify any specific features of research- and innovation-related responsibility differing from corporate social responsibility. Differences in business RRI activities and the coverage of RRI dimensions may be explained by variations in the character of those businesses.

The sample size allowed us to draw only general lessons if we categorize the companies by their various characteristics. By the categories of size or ownership, we have a limited number of cases and each is influenced by sectoral differences (such as regulated and non-regulated). However, this attempt to group the companies provides some basis for suggesting larger scale empirical research including qualitative sampling. The novel value of this paper is that it not only investigates the implementation of RRI in business practice as one solid function, but it also reveals the relationship between the various dimensions of RRI within the companies. This approach allows us to identify certain dimensions of RRI that are well-known to the companies and which are properly addressed by various mechanisms. Another important value of the paper is that it calls attention to the differences in treating RRI stemming from the companies' characteristics. 
The study results in identifying which RRI dimensions are interesting for business organizations and could induce further studies, which will need to go into the details of how companies are performing within these dimensions.

Our exploratory research showed that some RRI topics are worth further investigation within a larger sample. New knowledge concerning barriers may contribute to improving RRI awareness and corporate practice at companies.

Practical lessons and recommendations: we do recommend that national research councils, EU research programs, and national and EU funding agencies of research and innovation facilitate the further increase of RRI awareness and activities with different tools. They need to broaden or introduce RRI criteria in project evaluation and funding decisions. This solution will prompt applicants to devote more attention to RRI. The recent application forms of the EU and of many member states contain questions on ethical issues, but other important elements of RRI are not among the evaluation criteria. The agencies can develop awards for RRI performance beyond sustainability and environmental issues. The same is true for monitoring RRI performance in terms of other dimensions.

Companies committed to both research and innovation, as well as the authorities, have tasks ahead of them to change the marginal role of RRI in strategic management thinking. Embedding RRI into the corporate culture may be supported with education and training as well as by efficient toolkits and RRI-focused funding criteria. All of these can help change the present situation.

These recommendations can be useful for the councils, businesses, and research organizations in Asian countries as well.

Within a few years, responsibility must lie at the heart of the innovation process at the majority of companies. Responsibility belongs to the day-to-day operating practices of all involved actors, as much as in the reflexive deliberation of decision-makers. These empirical findings provide good input for policymakers to further encourage enhanced responsibility in the business sector's research and innovation. For this purpose, the capacity for responsible innovation must be nurtured.

The paper is based on the empirical results collected by the work package 'RRI Trends' of the ResAgorA project (Responsible Research and Innovation in a Distributed Anticipatory Governance Frame. A Constructive Socio-Normative Approach). Funded by the EU's 7th Framework Program (GA nr. 321427). The authors would like to express their gratitude to Erich Griessler and Simone Arnaldi for their valuable comments during the first steps in the preparation of this research paper Furthermore, the authors are grateful for the work of the national correspondents who have prepared the 27 case studies as well as for the interviewees from the various companies who were ready to share their thoughts about the practices of RRI at their organizations.

\section{References}

Bessant J. (2013) Innovation in the Twenty-First Century. Responsible Innovation. Managing the responsible emergence of science and innovation in society (eds. R. Owen, J. Bessant, M. Heintz), Chichester: John Wiley \& Sons, pp. 1-25.

Buzás N., Lukovics M. (2015) A felelősségteljes innovációról (About responsible innovation) Közgazdasági Szemle, vol. LXII, no 4, pp. 438-456 (in Hungarian).

European Commission (2016) Horizon 2020. Work Programme 2016-2017. Topic 16: Science with and for Society, Brussels: European Commission.

Ghose T. (2015) Volkswagen Scandal: Why Is It So Hard to Make Clean Diesel Cars? Live Science, 24.09.2015. Available at: https://www.livescience.com/52284-volkswagen-scandal-clean-diesel-challenges.html, accessed 25.03.2017.

Grinbaum A., Groves C. (2013) What is "responsible" about "responsible innovation"? Responsible Innovation. Managing the responsible emergence of science and innovation in society (eds. R. Owen, J. Bessant, M. Heintz), Chichester: John Wiley \& Sons, pp. 119-142.

Grunwald A. (2011) Responsible Innovation: Bringing together Technology Assessment, Applied Ethics, and STS Research. Enterprise and Work Innovation Studies, vol. 7, pp. 9-31.

Mejlgaard N., Bloch C. (2012) Science in Society. Science and Public Policy, vol. 39, no 6, pp. 695-700. Available at: https://doi.org/10.1093/scipol/scs087, accessed 17.12.2016.

OECD, Eurostat (2005) Oslo Manual, Paris: OECD, Eurostat.

Owen R., Stilgoe J., Macnaghten P., Gorman M., Fisher E., Guston D. (2013) A Framework for Responsible Innovation. Responsible Innovation. Managing the responsible emergence of science and innovation in society (eds. R. Owen, J. Bessant, M. Heintz), Chichester: John Wiley \& Sons, pp. 27-50.

Pavie X., Scholten V., Carthy D. (2014) Responsible Innovation: From Concept to Practice, Singapore: World Scientific Publishing Company.

Rothwell R. (1992) Successful industrial innovation: Critical factors for the 1990s. R\&D Management, vol. 22, no 3, pp. 221-239.

Tsipouri L. (2012) Comparing innovation performance and science in society in the European member states. Science and Public Policy, vol. 39, no 6, pp. 732-740.

van den Hoven J. (2013) Value Sensitive Design and Responsible Innovation. Responsible Innovation. Managing the responsible emergence of science and innovation in society (eds. R. Owen, J. Bessant, M. Heintz), Chichester: John Wiley \& Sons, pp. 75-84.

von Schomberg R. (2013) A vision of responsible research and innovation. Responsible Innovation. Managing the responsible emergence of science and innovation in society (eds. R. Owen, J. Bessant, M. Heintz), Chichester: John Wiley \& Sons, pp. 51-74. 